\title{
Injectable thermosensitive hydrogel composite with surface-functionalized calcium phosphate as raw materials
}

This article was published in the following Dove Press journal:

International Journal of Nanomedicine

21 January 2014

Number of times this article has been viewed

\section{RangRang Fan' \\ XiaoHui Deng ${ }^{2}$ \\ LiangXue Zhou' \\ Xiang Gao' \\ Min Fan' \\ YueLong Wang' \\ Gang Guo'}

'State Key Laboratory of Biotherapy and Cancer Center, Department of Neurosurgery, West China Hospital, West China Medical School, Sichuan University, Chengdu, ${ }^{2}$ Department of Human Anatomy, Xinxiang Medical University, Xinxiang, People's Republic of China
Correspondence: Gang Guo State Key Laboratory of Biotherapy and Cancer Center, Department of Neurosurgery, West China Hospital, West China Medical School, Sichuan University, Chengdu 61004I, People's Republic of China

Tel +862885164063

Fax +862885164060

Email guogang@scu.edu.cn
Abstract: In this study, L-lactide was used to modify the tricalcium phosphate ( $\beta$-TCP) and tetracalcium phosphate (TTCP) surface which can form functionalized poly(l-lactic acid) (PLLA)-grafted $\beta$-TCP (g- $\beta$-TCP) and PLLA-grafted TTCP (g-TTCP) particles. The g- $\beta$-TCP and g-TTCP obtained were incorporated into a PEG-PCL-PEG (PECE) matrix to prepare injectable thermosensitive hydrogel composites. The morphology of the hydrogel composites showed that the g- $\beta$-TCP and g-TTCP particles dispersed homogeneously into the polymer matrix, and each hydrogel composite had a three-dimensional network structure. Rheologic analysis showed that the composite had good thermosensitivity. Changes in calcium concentration and $\mathrm{pH}$ in simulated body fluid solutions confirmed the feasibility of surface-functionalized calcium phosphate for controlled release of calcium. All the results indicate that $\mathrm{g}-\beta$-TCP/PECE and g-TTCP/PECE hydrogels might be a promising protocol for tissue engineering.

Keywords: injectable, thermosensitivity, surface functionalization, calcium phosphate, biocompatibility

\section{Introduction}

Hydrogels, ie, cross-linked hydrophilic polymer chains with three-dimensional structural networks, can be engineered to resemble the extracellular environment of body tissues in ways that enable their use in medical implants, as biosensors, and as drug delivery agents. ${ }^{1,2}$ Biodegradable stimuli-sensitive hydrogels can undergo volume or phase transition in response to environmental stimuli, such as temperature, $\mathrm{pH}$, ionic strength, pressure, or electric field. ${ }^{3}$ Among these, thermosensitive hydrogels which are free-flowing liquids at room temperature while forming a non-free-flowing gel at body temperature, have been widely used in the biomedical field. ${ }^{4-6}$ Their ability to absorb large amounts of water and their sensitivity to environmental temperature enable them to maintain certain shapes as well as achieve the goal of controlled drug release, tissue repair, and prevention of postoperative adhesions, especially in the physiologic body temperature range. ${ }^{7-10}$ In bone tissue engineering, ideal scaffolds should be equipped with surface properties that permit cell adhesion, differentiation, and proliferation, maintain desirable mechanical integrity, lack cytotoxicity, and have osteoconductivity. ${ }^{11}$ Thermosensitive hydrogels represent a promising modality to avoid using traditional noxious substances as an initiator of phase transition. ${ }^{12,13}$ In addition, many natural and synthetic hydrogels used in bone tissue engineering have been intensively studied, such as chitosan-based hydrogels ${ }^{14,15}$ and polyester copolymer hydrogels. ${ }^{16-18}$ 
It is well known that both poly(ethylene glycol) (PEG) and poly( $\varepsilon$-caprolactone) (PCL) are biodegradable and biocompatible materials approved by the US Food and Drug Administration. ${ }^{17,19,20}$ Moreover, PCL is a nontoxic material with hydrophobic characteristics. The chemical structure of the hydrophobic segments is an important factor in defining the thermogelling behavior, degradation, and release properties of thermosensitive PEGylated polyester copolymers. ${ }^{16}$ Thus, through combination of the respective advantages of PEG and PCL, the PEG-PCLPEG copolymer might have great potential application in the biomedical field.

Inorganic bioceramics such as hydroxyapatite $\left(\mathrm{Ca}_{10}\left(\mathrm{PO}_{4}\right)_{6}(\mathrm{OH})_{2}\right)$, tricalcium phosphate $\left(\beta-\mathrm{TCP}, \mathrm{Ca}_{3}\left(\mathrm{PO}_{4}\right)_{2}\right)$, and tetracalcium phosphate (TTCP, $\left.\mathrm{Ca}_{4}\left(\mathrm{PO}_{4}\right)_{2} \mathrm{O}\right)$, are commonly used as bone repair material, and provide a favorable environment for osteoconduction, protein adhesion, and osteoblast proliferation due to their excellent bioactivity and biocompatibility. ${ }^{21-23}$ TTCP $(\mathrm{Ca} / \mathrm{P}: 2.0)$ is the only calcium phosphate phase with a $\mathrm{Ca} / \mathrm{P}$ ratio greater than that of hydroxyapatite. $\beta$-TCP $(\mathrm{Ca} / \mathrm{P}: 1.5)$ occurs in various pathologic calcification and dental caries lesions. ${ }^{24}$ However, their application as implants is restricted by their brittleness and difficulty in molding. ${ }^{25}$ Adding calcium phosphate into a polymer matrix for preparation of calcium phosphate/ polymer composites is a common approach to solving these problems. ${ }^{26}$ It is reported that these kinds of biodegradable composite materials have improved mechanical properties and bioactivity, and are able to induce cells to attach or proliferate upon them. ${ }^{27,28}$ However, particle aggregates in composite materials are thought to trigger decreased adhesion between the two phases, resulting in an early failure at the interface.

To address the abovementioned drawbacks, the surface of calcium phosphate crystals has been successfully functionalized by PLLA in our previous study, and the results revealed that the surface grafted with TTCP particles had better dispersibility. ${ }^{29,30}$ In this study, $\beta$-TCP and TTCP particles were surface-modified by PLLA to obtain functionalized g- $\beta$-TCP and g-TTCP. The $\mathrm{g}$ - $\beta$-TCP and g-TTCP particles were then incorporated into PECE hydrogel to prepare thermal-sensitive $\mathrm{g}-\beta$-TCP/PECE and g-TTCP/PECE hydrogel composites. ${ }^{1} \mathrm{H}-\mathrm{NMR}$, Fourier transform infrared (FT-IR), X-ray diffraction, differential scanning calorimetry (DSC), and scanning electron microscopy were used to investigate the properties of these PECE copolymer, g- $\beta$ $\mathrm{TCP} / \mathrm{PECE}$, and g-TTCP/PECE composites. In vitro thermal sensitivity, $\mathrm{pH}$ changes, controlled release of calcium, and biocompatibility of the novel hydrogel composites were also studied.

\section{Materials and methods Raw materials}

PEG methyl ether $\left(M_{\mathrm{n}}=550\right), \varepsilon$-caprolactone, stannous octoate $\left(\mathrm{Sn}(\mathrm{Oct})_{2}\right)$, isophorone di-isocyanate, 3-(4, 5-dimethylthiazol2-yl)-2, 5-diphenyl tetrazolium bromide (MTT), and Dulbecco's modified Eagle's medium, purchased from SigmaAldrich (St Louis, MO, USA), were used without any further purification. TTCP (Brunauer-Emmett-Teller surface area $5.2308 \mathrm{~m}^{2} / \mathrm{g}$ ) and $\beta$-TCP (Brunauer-Emmett-Teller surface area $2.8364 \mathrm{~m}^{2} / \mathrm{g}$ ) were purchased from Nanjing Emperor Nano Materials Co, Ltd (Nanjing, People's Republic of China), and 1-lactide was obtained from Guangshui National Chemical Co (Guangshui, People's Republic of China). All other agents and solvents used in this work were of analytic reagent grade and used directly without further purification.

\section{Preparation of g- $\beta$-TCP/PECE and g-TTCP/PECE hydrogel composites}

Grafting polymerization of PLLA onto the hydroxyl groups of $\mathrm{g}$ - $\beta$-TCP or $\mathrm{g}$-TTCP was achieved via a ring-opening polymerization reaction according to our previous study. ${ }^{31}$ Briefly, the reaction vessel was placed in an oil bath at $140^{\circ} \mathrm{C}$ under a nitrogen atmosphere for 13 hours. A Soxhlet extractor was used to remove any non-grafted PLLA on the surface of the $\beta$-TCP and TTCP particles using dichloromethane as the solvent at $50^{\circ} \mathrm{C}$ for 24 hours. The purified $\mathrm{g}-\beta$-TCP and g-TTCP were dried to a constant weight at $40^{\circ} \mathrm{C}$ in a vacuum. The triblock PECE copolymer was synthesized in two steps, consistent with the literature. ${ }^{31}$ Briefly, a PEG methyl etherPCL diblock copolymer was synthesized from $\varepsilon$-caprolactone initiated by PEG methyl ether using $\mathrm{Sn}(\mathrm{Oct})_{2}$ as the catalyst by ring-opening copolymerization. The obtained PEG methyl ether-PCL was cross-linked using isophorone diisocyanate as the linker. The obtained PECE copolymer was dialyzed against deionized water for 3 days using cellulose dialysis tubing (Spectra/Por ${ }^{\circledR}$, Spectrum Laboratories Inc., Houston, TX, USA) with a cutoff molecular weight of 2,000. The aqueous PECE solution was then freeze-dried and kept in an airtight bag until use.

To prepare the g- $\beta$-TCP/PECE and g-TTCP/PECE hydrogel composites, $2.4 \mathrm{~g}$ of freeze-dried PECE powder and $7 \mathrm{~mL}$ of deionized water were added to a glass tube. After the PECE was fully dissolved in water, the total volume of solution was kept at $10 \mathrm{~mL}$ by adding water. The solution was incubated in a water bath at $60^{\circ} \mathrm{C}$ for 2 minutes, and then placed in 
an ice-water bath for another 5 minutes. After the solution became a transparent liquid, $0.6 \mathrm{~g}$ of $\mathrm{g}$ - $\beta$-TCP or g-TTCP powder was slowly added to the PECE solution. The mixture was then stirred and ultrasonicated for at least 30 minutes. Pure PECE hydrogel was prepared using a method similar to that described above.

\section{Characterization of physicochemical properties}

Thermogravimetric analysis was done with a heating rate of $10^{\circ} \mathrm{C}$ per minute from room temperature to $600^{\circ} \mathrm{C}$ on a TGA Q 500 series thermogravimetric analyzer (TA Instruments, New Castle, DE, USA). FT-IR spectra were taken on a Nicolet 6700 FT-IR spectrometer (Thermo Scientific, Waltham, MA, USA) in a range of $400-4,000 \mathrm{~cm}^{-1}$, using the $\mathrm{KBr}$ disk method. ${ }^{1} \mathrm{H}-\mathrm{NMR}$ spectroscopy was performed on a Varian 400 instrument (Varian Instruments, Palo Alto, CA, USA) at $400 \mathrm{mHz}$ using $\mathrm{CDCl}_{3}$ as the solvent and tetramethylsilane as the internal reference standard. X-ray powder diffraction patterns were recorded on an X'Pert Pro MPD DY1291 (Philips, Eindhoven, the Netherlands) diffractometer using graphitemonochromatized $\mathrm{Cu} \mathrm{K}$ radiation $(\lambda 0.1542 \mathrm{~nm} ; 40 \mathrm{kV}$; $40 \mathrm{~mA}$ ) at a scanning rate of $4^{\circ}$ per minute. DSC was performed using a differential scanning calorimeter (Netschz 204, Netschz, Selb, Germany) at a heating rate of $10^{\circ} \mathrm{C}$ per minute. The morphology of the hydrogel composites was examined using a scanning electron microscope (JSM-5900LV, JEOL, Tokyo, Japan) at $20 \mathrm{kV}$. All samples were gold-coated prior to examination by scanning electron microscopy.

\section{Characterization of rheologic and sol-gel-sol phase transition of hydrogel composites}

Rheologic measurement of the hydrous hydrogel composites was carried out using a Gemini rheometer (Malvern Instruments, Malvern, UK). The samples were placed between parallel $40 \mathrm{~mm}$ diameter plates with a gap of $1 \mathrm{~mm}$. The heating rate was set as $2^{\circ} \mathrm{C}$ per minute in the range of $10^{\circ} \mathrm{C}-60^{\circ} \mathrm{C}$. The storage modulus $\left(G^{\prime}\right)$, loss modulus $\left(G^{\prime \prime}\right)$, and complex viscosity $\left(\eta^{*}\right)$ were measured to characterize the kinetics of hydrogel formation as a function of temperature. A frequency of $1 \mathrm{~Hz}$ and a strain of $1 \%$ were applied in order to maintain a linear viscoelastic region.

In this study, each sample of a given concentration was prepared by dissolving a sample of known amount in deionized water at a designated temperature. The volume of the solution was kept at $1 \mathrm{~mL}$ in total, regardless of the concentration. After being incubated in a water bath at $0^{\circ} \mathrm{C}$ for 15 minutes, the hydrated samples were slowly heated at a rate of $0.5^{\circ} \mathrm{C}$ per minute from $0^{\circ} \mathrm{C}$ to the temperature at which precipitation occurred. A sol-gel-sol phase transition diagram of triblock copolymer hydrogels was recorded using the test tube-inverting method with a $10 \mathrm{~mL}$ tightly screwcapped vial with an inner diameter of $13 \mathrm{~mm}$. The sol-gel-sol transition was visually observed by inverting the vials, and the conditions of sol and gel were defined as "flow liquid sol" and "no flow solid gel" in one minute, respectively.

\section{Release of calcium from hydrogels and in vitro $\mathrm{pH}$ change}

Simulated body fluid was buffered at $\mathrm{pH} 7.4$ with tris(hydroxymethyl) aminomethane $\left(\left(\mathrm{CH}_{2} \mathrm{OH}\right)_{3} \mathrm{CNH}_{2}\right)$ and $1 \mathrm{M}$ hydrochloric acid $(\mathrm{HCl})$ at $36.5^{\circ} \mathrm{C}$. The composition of the simulated body fluid is shown in Table 1 . The in vitro calcium concentrations and $\mathrm{pH}$ change were performed in simulated body fluid on a stir plate at a constant temperature $\left(37^{\circ} \mathrm{C}\right)$. Briefly, the samples were placed in a dialysis bag (molecular mass cutoff 800-1,000) and incubated in $20 \mathrm{~mL}$ of simulated body fluid at $37^{\circ} \mathrm{C}$ with gentle shaking. At set time intervals, the following characteristics were investigated: $\mathrm{pH}$ value at the end of each incubation period, measured using a $\mathrm{pH}$ meter (PHS-3C, Shanghai Lida Instrumentation Co, Shanghai, People's Republic of China); calcium concentrations in simulated body fluid solution, recorded on a SpectrAA 220FS (Varian Instruments) as a function of soaking time.

\section{Cytotoxicity assay of g- $\beta$-TCP/PECE and g-TTCP/PECE hydrogel composites}

Cytotoxicity was evaluated according to the 2009 International Organization for Standardization 10993-5 guideline. ${ }^{32}$ Hydrous g- $\beta$-TCP/PECE and g-TTCP/PECE hydrogel composites $\left(6 \mathrm{~cm}^{2} / \mathrm{mL}\right.$ of culture medium) were extracted using Dulbecco's modified Eagle's medium containing 10\% $(v / v)$ fetal bovine serum for 72 hours at $37^{\circ} \mathrm{C}$. The extracts were then diluted with Dulbecco's modified Eagle's medium

Table I Composition of simulated body fluid solution

\begin{tabular}{ll}
\hline Reagent & Amount/L \\
\hline $\mathrm{NaCl}$ & $8.035 \mathrm{~g}$ \\
$\mathrm{NaHCO}$ & $0.355 \mathrm{~g}$ \\
$\mathrm{KCl}$ & $0.225 \mathrm{~g}$ \\
$\mathrm{~K}_{2} \mathrm{HPO}_{4} \cdot 3 \mathrm{H}_{2} \mathrm{O}$ & $0.231 \mathrm{~g}$ \\
$\mathrm{MgCl}_{2} \cdot 6 \mathrm{H}_{2} \mathrm{O}$ & $0.311 \mathrm{~g}$ \\
$\mathrm{HCl}$ & $39 \mathrm{~mL}$ \\
$\mathrm{CaCl}_{2}$ & $0.292 \mathrm{~g}$ \\
$\mathrm{NaSO}_{4}$ & $0.072 \mathrm{~g}$ \\
Tris & $6.118 \mathrm{~g}$ \\
\hline
\end{tabular}

Abbreviation: Tris, tris(hydroxymethyl) aminomethane. 
( $10 \%$ fetal bovine serum), and a series of the extract dilutions $[1 \%, 2 \%, 5 \%, 10 \%, 20 \%, 40 \%, 60 \%, 80 \%, 100 \%(\mathrm{v} / \mathrm{v})]$ were collected. The L929 cells were incubated with the leachates of different concentrations ( $n=3$ ) for 24 hours and 48 hours, respectively. At predetermined time points, $20 \mu \mathrm{L}$ of MTT was added to each well and the cells were further incubated for another 4 hours at $37^{\circ} \mathrm{C}$. The supernatant was fully removed and $150 \mu \mathrm{L}$ of dimethyl sulfoxide was added to each well, oscillating for 30 minutes. The absorbance of each well was measured at $570 \mathrm{~nm}$ using an enzyme-linked immunosorbent assay microplate reader (Bio-Rad, Hercules, CA, USA). A mean value was obtained from four test runs.

\section{Statistical analysis}

The results of all data sets were analyzed using one-way analysis of variance. The results are represented as the mean value \pm standard deviation of triplicate samples unless otherwise stated. Differences between datasets were considered statistically significant for $P$-values less than 0.05 .

\section{Results}

\section{Synthesis and characterization}

The scheme in Figure 1A shows the process used to prepare the g- $\beta$-TCP/PECE and g-TTCP/PECE hydrogel composites.
Photographs of the aqueous hydrogel composites at room temperature and body temperature revealed the temperaturedependent sol-gel transition behavior of the PECE copolymer and the g- $\beta$-TCP/PECE and g-TTCP/PECE composites (Figure 1B and $\mathrm{C}$ ). The hydrogels flowed freely at lower temperature, and became nonflowing gels at body temperature. In Figure $1 \mathrm{C}$, there had obviously precipitate in TTCP/PECE (Figure 1C-d), evidently revealed that pure TTCP (nanografted) particles tended to aggregate, however, there had no precipitate in $\mathrm{g}$-TTCP/PECE and $\mathrm{g}-\beta$-TCP/PECE hydrogels (Figure $1 \mathrm{C}-\mathrm{b}$ and $1 \mathrm{C}-\mathrm{c}$ ), this suggested that surface-grafted TTCP had better dispersibility.

The amount of surface-grafted PLLA was determined as a weight loss percentage during heating (Figure 2). The weight losses from the $\beta$-TCP, TTCP, g- $\beta$-TCP, and g-TTCP at $600^{\circ} \mathrm{C}$ were $5.11 \%, 4.84 \%, 12.38 \%$, and $27.62 \%$, respectively. According to the equation whereby the grafting amount $(\%)=W(\%)-W_{0}(\%)$, where $W$ is the weight loss from $g-\beta$-TCP or g-TTCP, and $W_{0}$ is the weight loss from pure $\beta$-TCP or TTCP, it could be concluded that the PLLA grafting percentage for g- $\beta$-TCP and g-TTCP was $7.27 \%$ and $22.78 \%$, respectively.

As shown in the FT-IR spectra (Figure 3A), the new bands of the g- $\beta$-TCP and the g-TTCP at about $2,994 \mathrm{~cm}^{-1}$ and $1,759 \mathrm{~cm}^{-1}$ were attributed to vibration of the $-\mathrm{CH}$ and the $\mathrm{C}=\mathrm{O}$ bonds and the broad peak at $3,300-3,500 \mathrm{~cm}^{-1}$ was
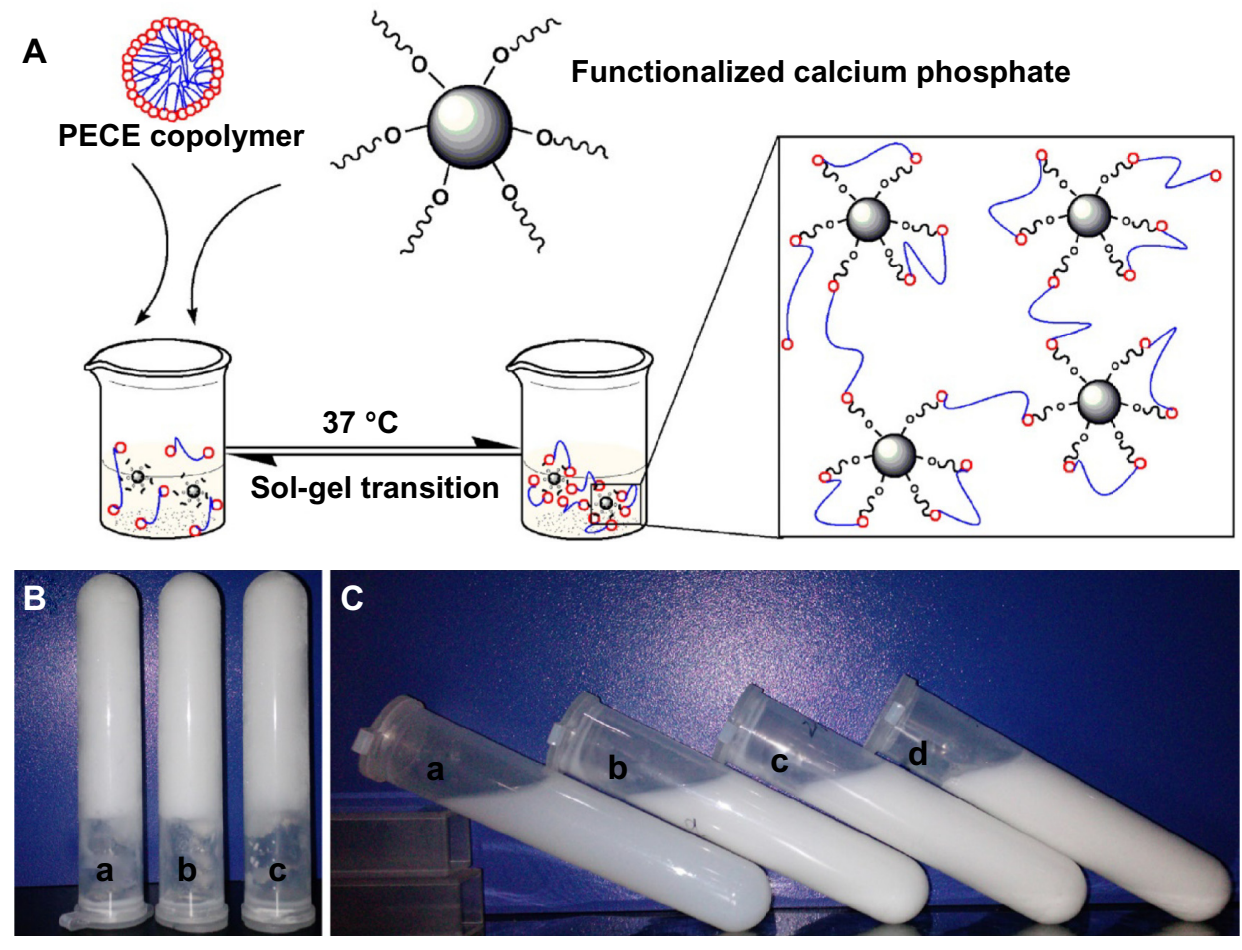

Figure I (A) Synthesis scheme for the hydrogel composites. (B) Thermosensitive hydrogel formation of pure PECE (a); g-TTCP/PECE (b); $\beta$-TCP/PECE (c) at $37^{\circ} \mathrm{C} ;(\mathbf{C})$ thermosensitive hydrogel formation of pure PECE (a); g-TTCP/PECE (b); $\beta$-TCP/PECE(c); and TTCP/PECE (d) at $10^{\circ} \mathrm{C}$.

Abbreviations: $\beta$-TCP, tricalcium phosphate; TTCP, tetracalcium phosphate; PEG, poly(ethylene glycol); PCL, poly( $(\varepsilon$-caprolactone); PECE, PEG-PCL-PEG; g- $\beta$-TCP, poly(l-lactic acid)-grafted $\beta$-TCP; g-TTCP, poly(l-lactic acid)-grafted TTCP. 


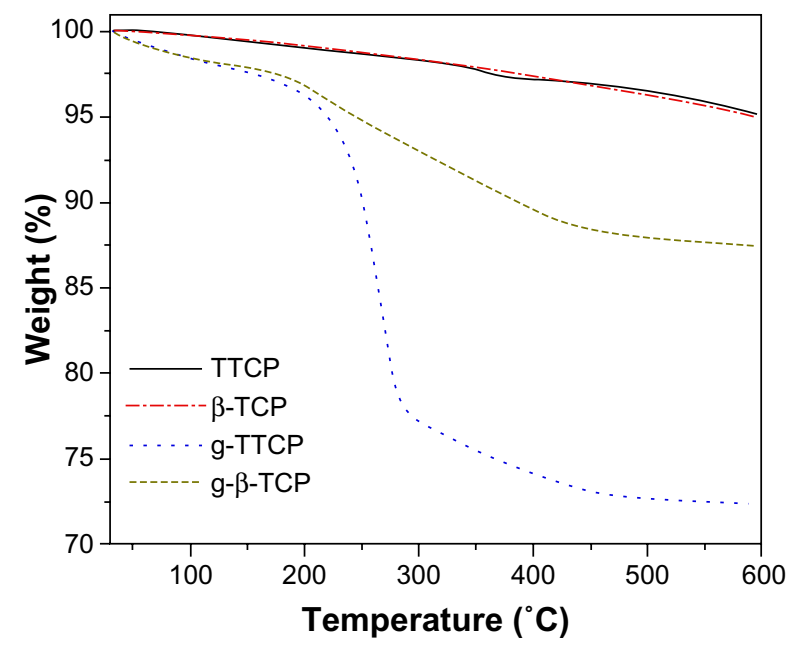

Figure 2 Thermogravimetric curves for pure TTCP, $\beta$-TCP, g-TTCP, and g- $\beta$-TCP. Abbreviations: $\beta$-TCP, tricalcium phosphate; TTCP, tetracalcium phosphate; $g-\beta$ TCP, poly(l-lactic acid)-grafted $\beta$-TCP; g-TTCP, poly(l-lactic acid)-grafted TTCP.

related to the $\mathrm{OH}$ - from the PLLA and the absorbed water. Figure 3B shows the FT-IR spectra of bare PECE and the $\mathrm{g}-\beta$-TCP/PECE and g-TTCP/PECE hydrogel composites. In the ${ }^{1} \mathrm{H}-\mathrm{NMR}$ spectra (Figure 4), the two weak peaks at $4.20 \mathrm{ppm}$ and $3.82 \mathrm{ppm}$ belonged to methylene protons of $-\mathrm{O}-\mathrm{CH}_{2}-\mathrm{CH}_{2}-$ in PEG in the PEG methyl ether end unit which linked with PCL blocks. The $M_{\mathrm{n}}$ value for the obtained PECE copolymer was 3,150 according to the ${ }^{1} \mathrm{H}-\mathrm{NMR}$ peaks of $3.60 \mathrm{ppm}$ and $4.06 \mathrm{ppm}$.

Peaks observed in the X-ray diffraction profiles at $2 \theta=26.5^{\circ}, 31.0^{\circ}$, and $34.3^{\circ}$ were the characteristic diffraction peaks of $\mathrm{g}$ - $\beta$-TCP. In the $\mathrm{g}$-TTCP pattern, obvious peaks were observed at $2 \theta=29.2^{\circ}, 29.8^{\circ}, 31.1^{\circ}$, and $32.4^{\circ}$. Two strong peaks could be seen at $21.5^{\circ}$ and $23.9^{\circ}$ for the crystalline peaks of the PECE copolymer matrix. Several diffraction peaks were observed in the $\mathrm{g}-\beta$-TCP/PECE and g-TTCP/PECE hydrogel composites (c and d) in Figure 3C, and they were at the same location as those of the g- $\beta$-TCP powder, g-TTCP powder, and PECE hydrogels.

Thermal properties, such as the melting temperature $\left(T_{m}\right)$ and crystallization temperature $\left(T_{c}\right)$, of pure PECE and the composites were measured by DSC. Figure $5 \mathrm{~A}$ indicates that the crystallization temperature of the samples was in the range of $18^{\circ} \mathrm{C}-22^{\circ} \mathrm{C}$, and decreased slightly from $21.5^{\circ} \mathrm{C}$ to $20.5^{\circ} \mathrm{C}$ and $19.0^{\circ} \mathrm{C}$ when g- $\beta$-TCP and g-TTCP particles were added, the reason for which might be that addition of g- $\beta$-TCP and g-TTCP particles to the PECE matrix weakens the crystallinity of the PECE chains.

The g- $\beta$-TCP and g-TTCP particle sizes were about 2-8 $\mu \mathrm{m}$ and $0.5-0.8 \mu \mathrm{m}$, respectively (Figure 6). It can be seen that the inner pores of the PECE hydrogel were interconnected,
A

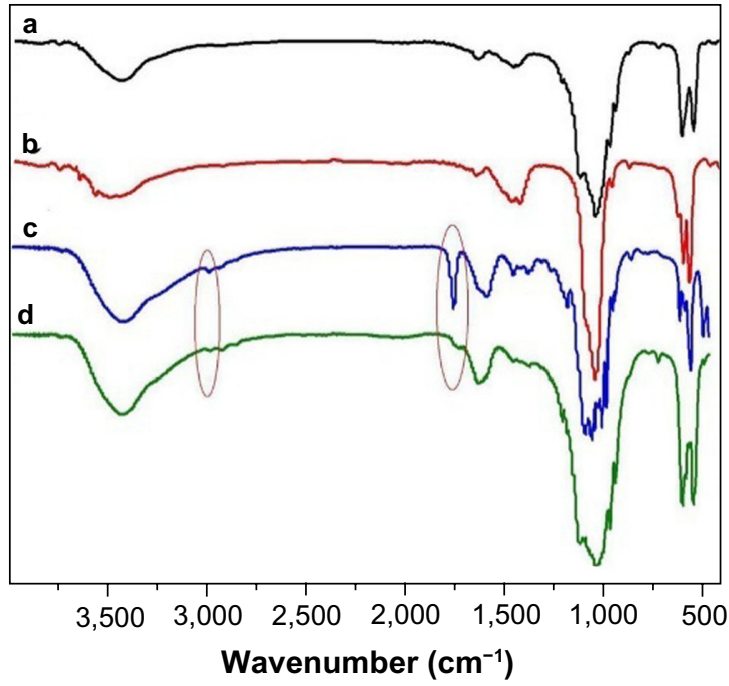

B

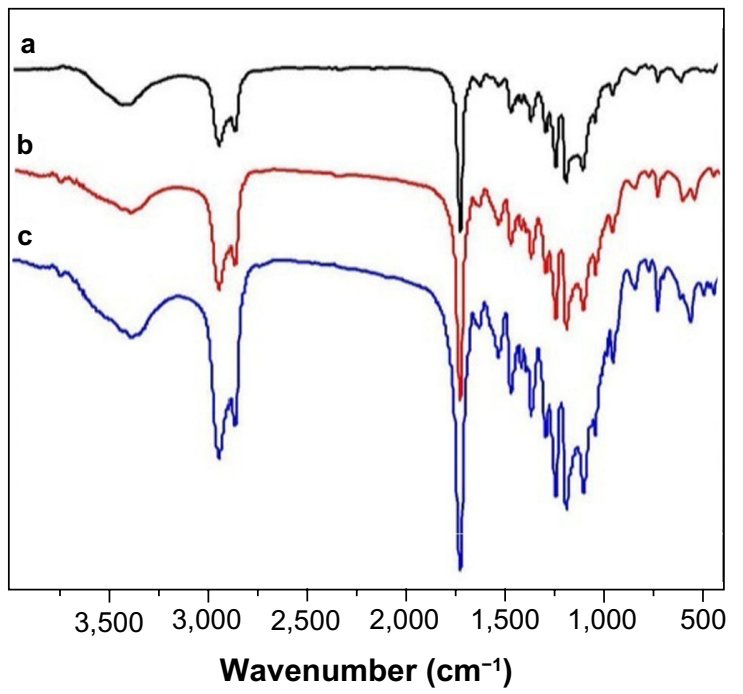

C

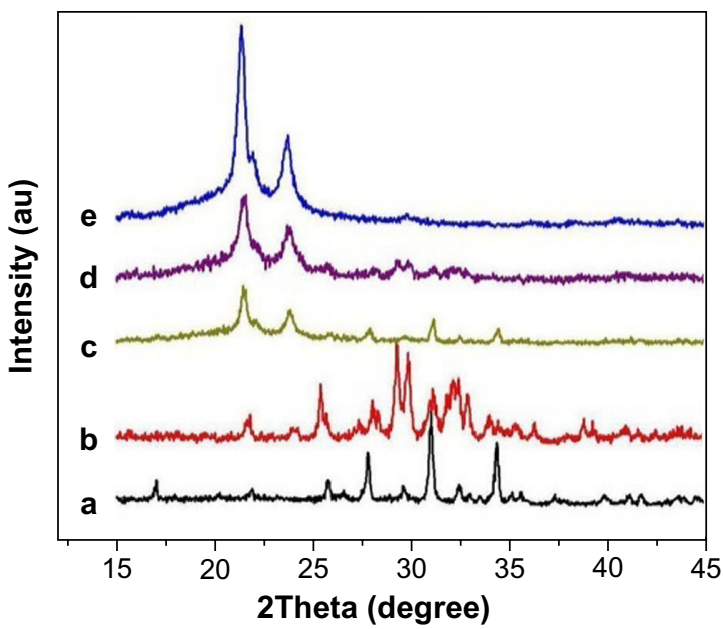

Figure 3 (A) FT-IR spectra for pure TTCP (a); $\beta$-TCP (b); g-TTCP (c); and g- $\beta$ TCP (d). (B) FT-IR spectrum for PECE (a); g-TTCP/PECE (b); and g- $\beta$-TCP/PECE (c). (C) X-ray diffraction patterns for g- $\beta$-TCP (a); g-TTCP (b); g- $\beta$-TCP/PECE (c); g-TTCP/PECE (d); and PECE (e).

Abbreviations: $\beta-T C P$, tricalcium phosphate; FT-IR, Fourier transform infrared; TTCP, tetracalcium phosphate; PEG, poly(ethylene glycol); PCL, poly(e-caprolactone); PECE, PEG-PCL-PEG; g- $\beta$-TCP, poly(l-lactic acid)-grafted $\beta$-TCP; g-TTCP, poly(llactic acid)-grafted TTCP. 


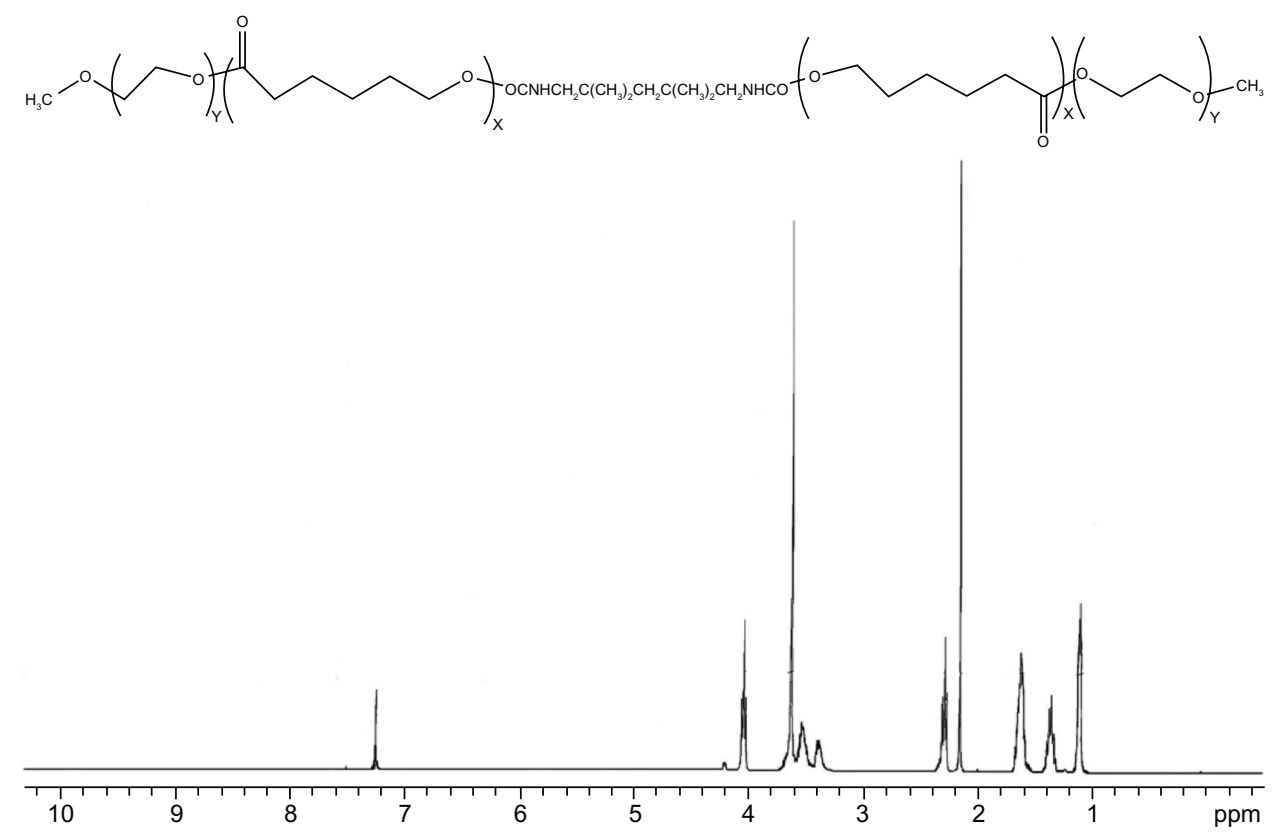

Figure 4 'H-NMR for PECE copolymer.

Abbreviations: PEG, poly(ethylene glycol); PCL, poly(E-caprolactone); PECE, PEG-PCL-PEG; ppm, parts per million; 'H-NMR, 'H nuclear magnetic resonance spectrum.

with irregular shapes and pore sizes ranging from $5 \mu \mathrm{m}$ to 20 $\mu \mathrm{m}$, as shown in Figure 6E. When the g- $\beta$-TCP and g-TTCP particles were added to the PECE matrix, the morphologies of the $\mathrm{g}-\beta$-TCP/PECE and g-TTCP/PECE hydrogel composites changed slightly, with the interconnected pores becoming fewer and smaller and the pores changing in integrity.

\section{Rheologic and temperature- dependent sol-gel-sol transition of hydrogel composites}

The mechanical properties of the PECE copolymer solution and aqueous g- $\beta$-TCP/PECE and g-TTCP/PECE hydrogel composites were examined by oscillatory rheologic tests as a function of temperature. Figure $7 \mathrm{~A}-\mathrm{C}$ shows changes in the $G^{\prime}, G^{\prime \prime}$, and $\eta^{*}$ for the hydrogels. $G^{\prime}$ in the sol state was less than $1 \mathrm{~Pa}$ and increased abruptly to greater than $100 \mathrm{~Pa}$ due to the sol-gel transition with increasing temperature. The dramatic decrease in $G^{\prime}$ at about $45^{\circ} \mathrm{C}$ demonstrates the gelsol transition of the aqueous copolymer solution. Moreover, the sol-gel transition temperature of the resultant hydrogels shifted to a higher value when $\mathrm{g}-\beta$-TCP and g-TTCP were added. The sol-gel-sol transition phase diagram of the hydrogels is shown in Figure 7D. All aqueous samples showed solgel transition and gel-sol transition. The "sol-gel" transition temperature of aqueous g- $\beta$-TCP/PECE and g-TTCP/PECE hydrogel composites decreased as $\mathrm{g}-\beta$-TCP and the $\mathrm{g}$-TTCP was added, and the "gel-sol" transition temperature shifted to a higher value at the same time.

\section{In vitro degradation and release study}

The $\mathrm{pH}$ and calcium concentration values in simulated body fluid solution as a function of soaking time are shown in Figure 8 . For g- $\beta$-TCP and g-TTCP, the $\mathrm{pH}$ of the solution increased steadily during degradation, and reached 7.93 and 8.05, respectively, after one day. Values for the g- $\beta$-TCP/PECE and g-TTCP/PECE hydrogels increased from 7.45 to 7.91 and 7.93 , respectively, but decreased slowly after one day (Figure 8A). As a whole, the curves for different calcium concentration could be divided into three stages during the whole immersion period: calcium concentration presented a increase firstly; and decreased secondly; then calcium concentration increased slowly. (Figure 8B).

\section{Cytotoxicity assay of composite hydrogel}

The results of the MTT assay are shown in Figure 9. After 24 hours of incubation, L929 cells showed well viability in all the leachates. Percent viability of the L929 cells decreased slightly as the concentration of leachates increased; however, the absorbance was not significantly different from that of the negative control. Over the test duration of 48 hours, the absorbance of all samples increased further with no noticeable difference between the groups. As observed in the MTT assay, the toxicity of the g- $\beta$-TCP/PECE and g-TTCP/PECE hydrogel composites to L929 cells was acceptably low based on cell viability and proliferation. 

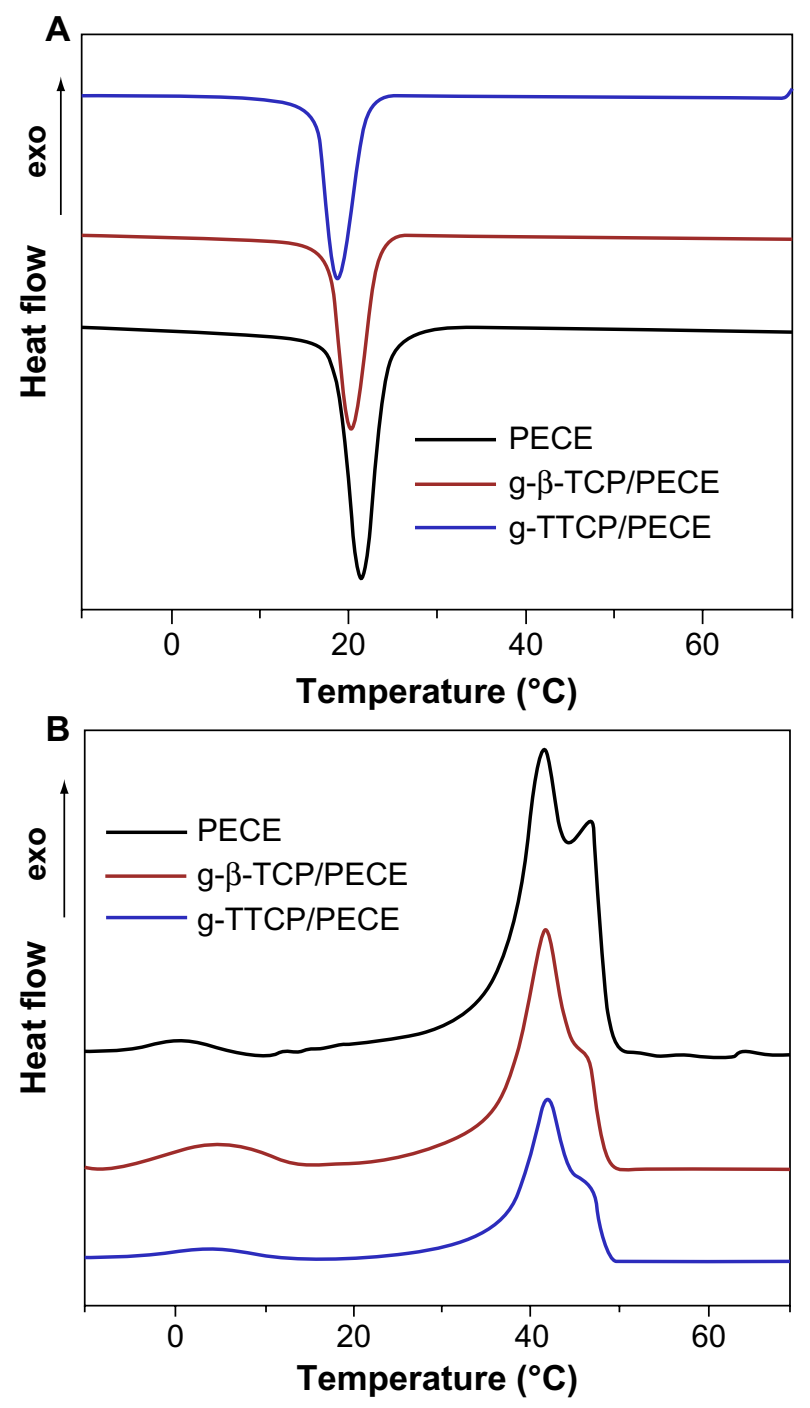

Figure 5 DSC profiles for PECE, g- $\beta$-TCP/PECE, and g-TTCP/PECE hydrogel composites. (A) DSC thermograms recorded from the first cooling cycle. (B) DSC thermograms recorded from the second heating cycle.

Abbreviations: DSC, differential scanning calorimetry; PEG, poly(ethylene glycol); PCL, poly( $\varepsilon$-caprolactone); PECE, PEG-PCL-PEG; g- $\beta$-TCP, poly(l-lactic acid)-grafted tricalcium phosphate; g-TTCP, poly(l-lactic acid)-grafted tetracalcium phosphate.

\section{Discussion}

Over recent decades, researchers have paid a lot of attention to in situ calcium phosphate/polymer injection hydrogels for repair of bone defects. ${ }^{33,34}$ Among these, thermal-sensitive hydrogels are the mostly extensively studied because they can be injected as a liquid with in situ gel formation at physiologic temperature. In previous studies, Fan et $\mathrm{al}^{31}$ and Gong et $\mathrm{l}^{35}$ have reported the PECE thermosensitive hydrogels, and they were proven to be injectable, biocompatible, and bioabsorbable. However, their studies were mainly focused on the use of hydrogels as a drug delivery system. In this study, we combined thermosensitive PECE hydrogel with an inorganic filler to prepare the injectable and thermosensitive hydrogel composites, with the expectation that they would be applied in the tissue engineering field.

It is well known that the interfacial strength between calcium phosphate and a polymer is a key factor in the construction of such a composite. Much effort has been made to improve composite interfacial bonding based on the fact that a layer of hydroxyl groups covers the outermost surface of the calcium phosphate particles. ${ }^{36}$ Further, the affinity of the particle surface for the polymer matrix could be improved to some extent in certain ways. Thus, surface functionalization of $\beta$-TCP and TTCP might play a significant role in producing well dispersed calcium phosphate/polymer hydrogel composites. To the best of the authors' knowledge, there has not been any literature reported concerning the use of $\beta$-TCP and TTCP in surface modification of PECE hydrogel composite scaffolds. In this study, TTCP and $\beta$-TCP particles were surface-functionalized by ring-opening polymerization and novel g- $\beta$-TCP/PECE and g-TTCP/PECE hydrogel composites were prepared.

The amount of PLLA grafted onto the surface of $\beta$-TCP and g-TTCP at 13 hours was $7.27 \%$ and $22.78 \%$, respectively. The percentage grafting can be adjusted to control the release of calcium to apply to different clinical patients according to our studies. From the results of FT-IR analysis, the characteristic band at $2,994 \mathrm{~cm}^{-1}$ and $1,759 \mathrm{~cm}^{-1}$ confirms the formation of $\mathrm{g}-\beta$-TCP and g-TTCP. The ${ }^{1} \mathrm{H}$-NMR result is in agreement with that reported by Gong et al, indicating that the PECE copolymer was prepared successfully. ${ }^{35}$

The pure PECE copolymer had two strong characteristic peaks at $21.3^{\circ}$ and $23.7^{\circ}$, indicating that this copolymer is only partly crystalline (Figure $3 \mathrm{C}$ ). Two peaks could be observed for the g- $\beta$-TCP/PECE and g-TTCP/PECE hydrogel composites, but their intensity was markedly decreased. It might be interactions between the g- $\beta$-TCP and g-TTCP particles and the macromolecular chains in PECE that weaken the crystallinity of PECE.

Two endothermic peaks at $39^{\circ} \mathrm{C}-43^{\circ} \mathrm{C}$ and $46^{\circ} \mathrm{C}-48^{\circ} \mathrm{C}$ on the heating trace and one exothermic peak at $18^{\circ} \mathrm{C}-22^{\circ} \mathrm{C}$ on the cooling trace were attributed to melting of the PCL segment followed by melting of the recrystallized PCL domain during the heating process (Figure 5A); this was similar to the two endothermic peaks of the PEG-PCL copolymer composed of low molecular weight PEG and PCL. ${ }^{37}$ Moreover, the two melting temperatures of the $\mathrm{g}-\beta$-TCP/PECE and g-TTCP/PECE hydrogel composites were higher than those of pure PECE copolymer. It might be the interactions between the g- $\beta$-TCP and g-TTCP particles and the PECE matrix that blocked the thermal motion of the PECE chains. The decrease 

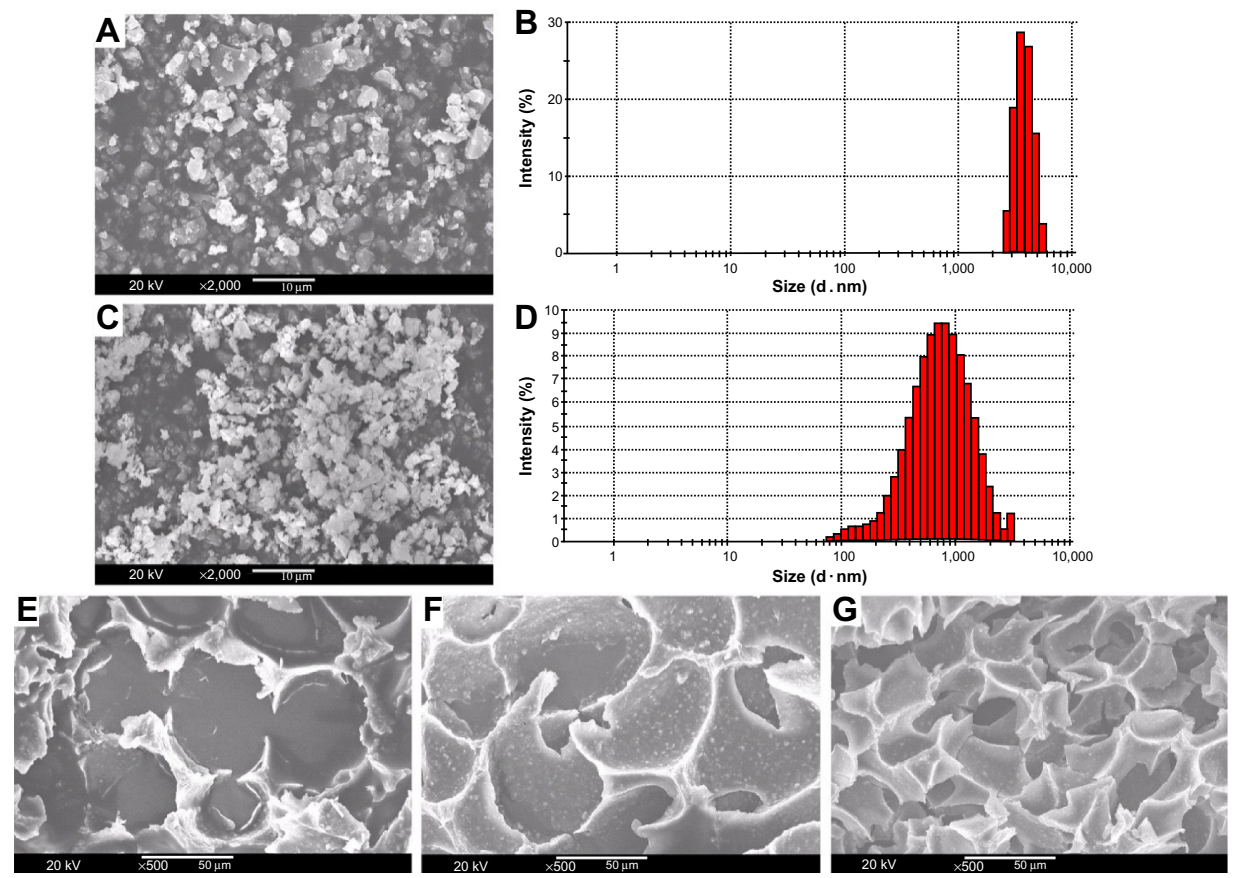

Figure 6 Scanning electron microscopic observations and particle size of g- $\beta$-TCP (A and B) and g-TTCP (C and D), cross-sectional morphologies of pure PECE (E), g-TTCP/PECE (F), and g- $\beta$-TCP/PECE and hydrogel composites $(\mathbf{G})$.

Abbreviations: PEG, poly(ethylene glycol); PCL, poly( $\varepsilon$-caprolactone); PECE, PEG-PCL-PEG; g- $\beta$-TCP, poly(l-lactic acid)-grafted tricalcium phosphate; $g$-TTCP, poly(l-lactic acid)-grafted tetracalcium phosphate.

A

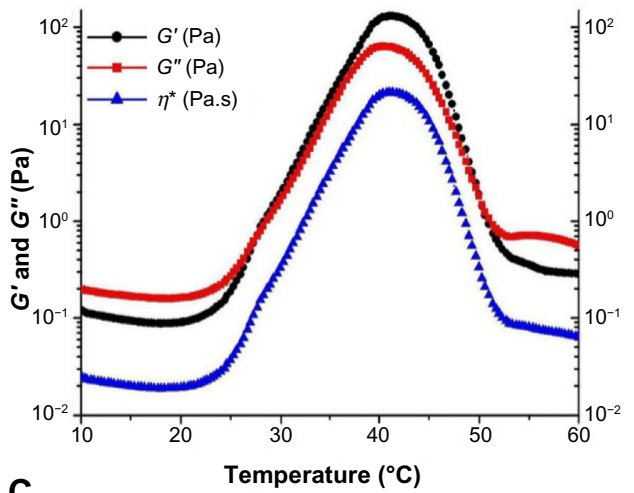

C

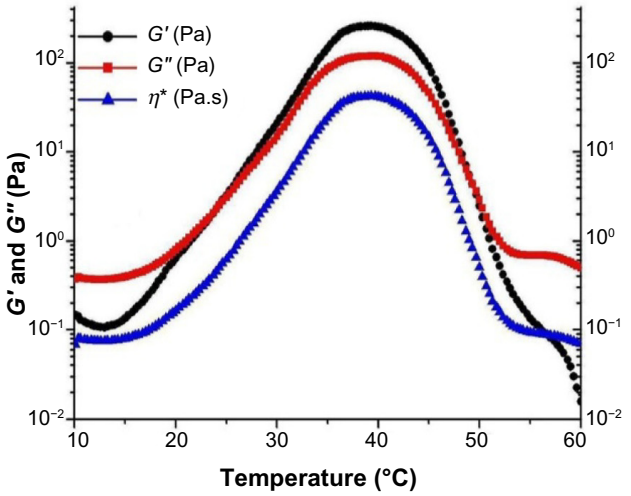

B

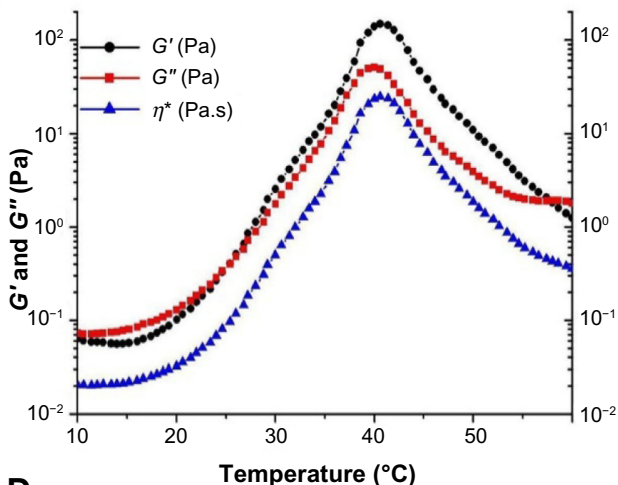

D

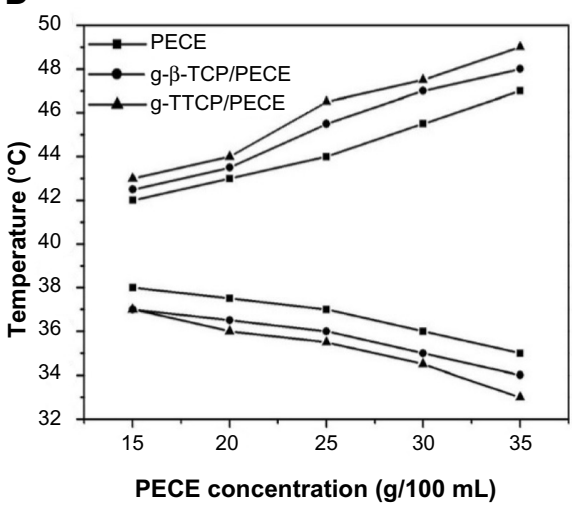

Figure 7 Rheologic results showing changes in storage modulus ( $G$ ), loss modulus ( $\left.G^{\prime}\right)$, and complex viscosity $\left(\eta^{*}\right)$ of samples upon heating. (A) PECE, (B) g- $\beta$-TCP/PECE, and (C) g-TTCP/PECE. (D) Sol-gel-sol transition phase diagram of PECE hydrogel, and g-TTCP/PECE and g- $\beta$-TCP/PECE hydrogel composites.

Abbreviations: PEG, poly(ethylene glycol); PCL, poly( $\varepsilon$-caprolactone); PECE, PEG-PCL-PEG; g- $\beta$-TCP, poly(I-lactic acid)-grafted tricalcium phosphate; g-TTCP, poly(I-lactic acid)-grafted tetracalcium phosphate. 

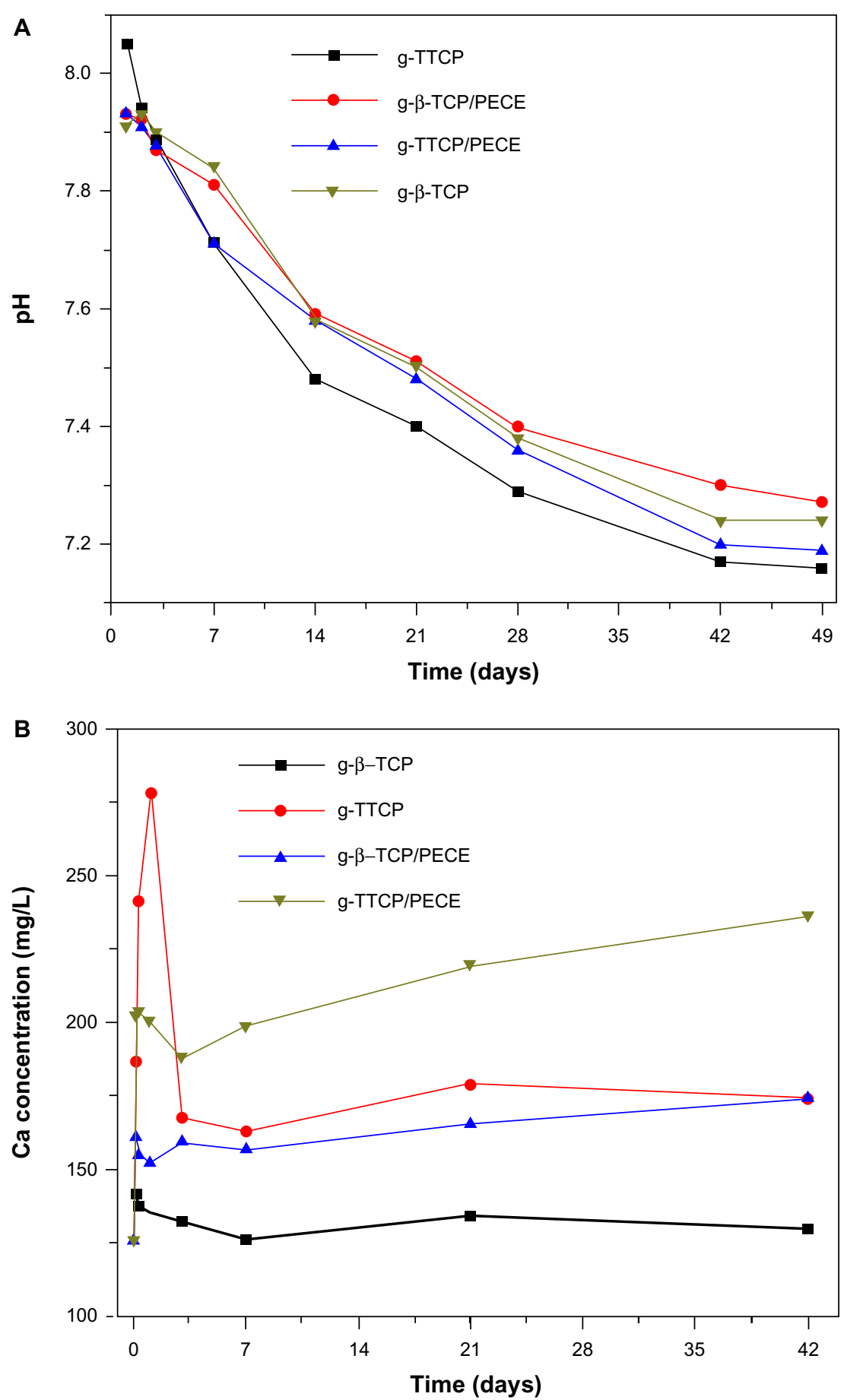

Figure $8 \mathrm{pH}(\mathbf{A})$ and calcium concentration (B) in simulated body fluid solution as a function of soaking time.

Abbreviations: PEG, poly(ethylene glycol); PCL, poly( $\varepsilon$-caprolactone); PECE, PEG-PCL-PEG; g- $\beta$-TCP, poly(l-lactic acid)-grafted tricalcium phosphate; g-TTCP, poly(l-lactic acid)-grafted tetracalcium phosphate.

in crystallization temperature might due to dispersion of the g- $\beta$-TCP and g-TTCP particles in the PECE matrix, restraining crystallization of the PECE domains. The $\Delta H_{c}$ decreased when g- $\beta$-TCP and g-TTCP were incorporated into PECE, also suggesting decreased crystallinity that would result in increased solubility of the composites. This might be the reason why the temperature ranges in the gel state became wider when g- $\beta$-TCP and g-TTCP particles were added.

The results shown in Figure 1B and Figure 1C suggest that the $\mathrm{g}-\beta$-TCP/PECE and g-TTCP/PECE hydrogel composites 
A

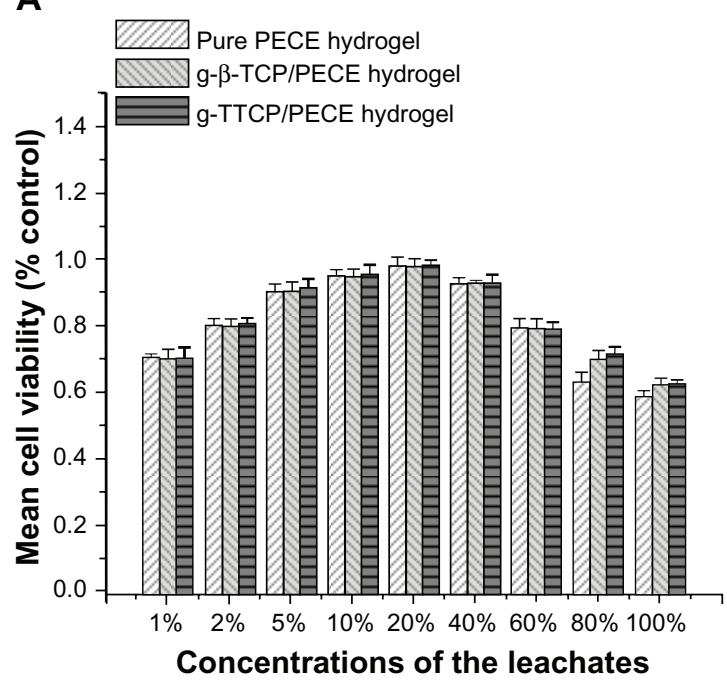

B

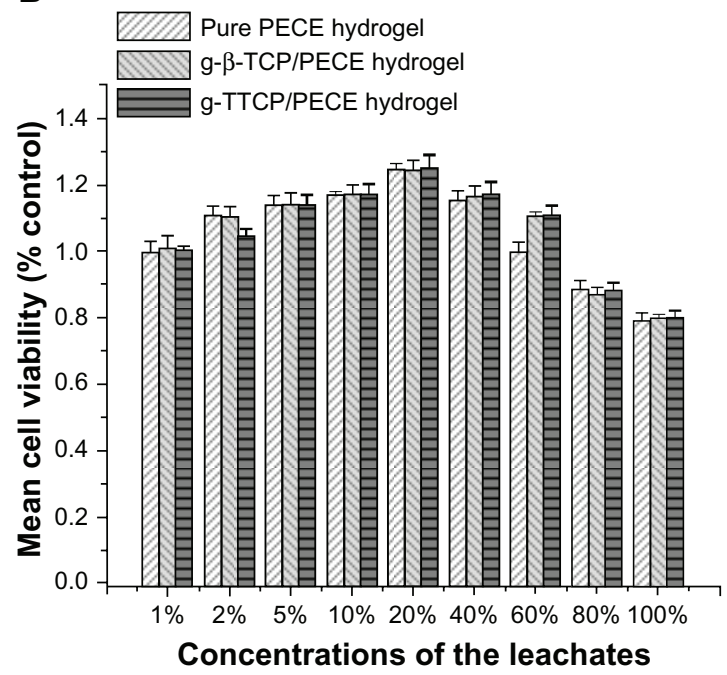

Figure 9 Rat L929 cytotoxicity evaluation in different concentration leachates from hydrogel composites cultured for 24 hours (A) and 48 hours (B). Error bars represent the standard deviation; $n=3$. Data are expressed as the mean \pm standard deviation. Significant at the $* P<0.05$ level when pure $P E C E$ was the control.

Abbreviations: PEG, poly(ethylene glycol); PCL, poly( $\varepsilon$-caprolactone); PECE, PEG-PCL-PEG; g- $\beta$-TCP, poly(I-lactic acid)-grafted tricalcium phosphate; g-TTCP, poly(I-lactic acid)-grafted tetracalcium phosphate.

had better dispersibility. The three-dimensional network structure of all samples formed is attributable to hydrophobic interaction of the PCL segments in the PECE chains (Figure 6). In addition, the interconnected porous structures suggest that $\mathrm{g}-\beta$-TCP/PECE and g-TTCP/PECE hydrogel composites are potentially useful as an injectable scaffold for cell growth and migration in a polymer matrix. We also found that the pores became smaller when g-TTCP was added because the TTCP particle sizes were smaller. The decrease in cold crystallization temperature might be another reason for the decreased volume of the interconnected pores.

Rheologic measurement confirmed the thermal sensitivity of PECE and the g- $\beta$-TCP/PECE and g-TTCP/PECE hydrogel composites (Figure 7A-C). The gelation temperature of the hydrogel composites was higher than that of pure PECE hydrogel. A possible explanation is that the $\mathrm{g}-\beta-\mathrm{TCP}$ and g-TTCP particles could change the specific hydrophobic interactions between the PCL block and the PEG block of the PECE copolymer. The formation of hydrogen bonds between the g- $\beta$-TCP and g-TTCP and PECE chains facilitated the gelation process.

The results shown in the sol-gel-sol transition phase diagram reveal that the temperature ranges over which the samples remained in the gel state widened following addition of g- $\beta$-TCP and g-TTCP particles (Figure 7D). ${ }^{2}$ This explains the interactions between the $\mathrm{g}-\beta$-TCP and g-TTCP particles and the PECE polymer matrix described above.

The change in $\mathrm{pH}$ was due to the release of $\mathrm{OH}^{-}$after degradation of $\mathrm{g}-\beta$-TCP and $\mathrm{g}$-TTCP neutralized the acid resulting from degradation of PECE. It also indicates that incorporation of g- $\beta$-TCP and g-TTCP could prevent degradation of PECE. The surface-functionalized calcium phosphate, involving different degrees of grafting of a poly(lactic acid) oligomer chain onto the surface of the polygon-shaped $\beta$-TCP and TTCP particles, resulted in controlled release of calcium. The change in calcium concentration was because that SBF was supersaturated and any ionic dissociation in the SBF would break this equilibrium. First, the main reason for the increase in calcium concentration during this phase was the dominance of dissolution of the composite because of the dissolution behavior of phosphate. Second, dissolution of the composite surface transformed into precipitation and precipitation of phosphate became the main process due to the decrease in calcium ions in simulated body fluid at this time. Finally, the calcium concentration was increased due to dissolution of bone-like apatite which could create many nucleation sites on the surface of the composites. ${ }^{38}$

The cytotoxicity of the PECE copolymer was evaluated by MTT assay in L929 cells, which depended on the dose of leachates from the g- $\beta$-TCP/PECE and g-TTCP/PECE composites. From the MTT data, we can see that all the samples showed an upward trend, suggesting that osteoblasts grew in the leachates of the g- $\beta$-TCP/PECE and g-TTCP/ PECE composites. As shown in Figure 9, osteoblast proliferation was significant when the weight ratio of the leachates of the g- $\beta$-TCP/PECE and g-TTCP/PECE composites was lower than $20 \mathrm{wt} \%$. Cell viability was higher than $59 \%$, even when the weight ratio of the leachates was $100 \%$. The cell proliferation behavior suggests that the $\mathrm{g}-\beta-\mathrm{TCP} / \mathrm{PECE}$ and 
g-TTCP/PECE composites have good biocompatibility and could be one of the best potential bone candidates in bone tissue engineering.

\section{Conclusion}

In this work, surface-functionalized g-TTCP and g- $\beta$-TCP particles were successfully prepared. Triblock copolymer PECE was combined with g- $\beta$-TCP and g-TTCP particles in order to prepare thermosensitive hydrogel composites. Rheologic measurements showed that the gelation points of the g- $\beta$-TCP/PECE and g-TTCP/PECE hydrogel composites were adequate for intracorporeal injection. The gelation temperature could be adjusted by adding g- $\beta$-TCP and g-TTCP particles into a PECE matrix. The three-dimensional structures of the $\mathrm{g}-\beta-\mathrm{TCP} / \mathrm{PECE}$ and g-TTCP/PECE hydrogel composites show that they could be used as a scaffold material for cell proliferation. Therefore, the $\mathrm{g}-\beta$-TCP/PECE and g-TTCP/PECE hydrogel composite system is a prospective candidate as an injectable biomaterial for tissue engineering. Although the concept of injectable and thermoresponsive hydrogel nanocomposites has been introduced in this study, more research is needed to validate the application of such systems in bone regeneration, possibly by investigating them with osteoblasts and in vivo animal tests in the future.

\section{Acknowledgments}

This work was supported financially by the National S\&T Major Project (2011ZX09102-001-10 and 2013ZX09301304-007). The authors thank Wang Hui, Wen Jiqiu, Sun Huiqin, and Cheng Guanglei (Analytical and Testing Center, Sichuan University, Sichuan, People's Republic of China) for their help with scanning electron microscopy, $\mathrm{X}$-ray diffraction, FT-IR, and atomic absorption spectroscopy measurements.

\section{Disclosure}

The authors report no conflicts of interest in this work.

\section{References}

1. Seliktar D. Designing cell-compatible hydrogels for biomedical applications. Science. 2012;336:1124-1128.

2. Yu L, Ding JD. Injectable hydrogels as unique biomedical materials. Chem Soc Rev. 2008;37:1473-1481.

3. Xiang YQ, Peng ZQ, Chen DJ. A new polymer/clay nano-composite hydrogel with improved response rate and tensile mechanical properties. Eur Poly J. 2006;42:2125-2132.

4. Peng Q, Sun X, Gong T, et al. Injectable and biodegradable thermosensitive hydrogels loaded with PHBHHx nanoparticles for the sustained and controlled release of insulin. Acta Biomater. 2013;9:5063-5069.

5. Li YL, Rodrigues J, Tomás H. Injectable and biodegradable hydrogels: gelation, biodegradation and biomedical applications. Chem Soc Rev. 2012;41:2193-2221.
6. Lai PL, Lin CTY, Hong DW, et al. Development of bioactive thermosensitive polymer-ceramic composite as bone substitute. Chem Eng Sci. 2013;89:133-141.

7. Cheng YH, Yang SH, Liu CC, Gefen A, Lin FH. Thermosensitive hydrogel made of ferulic acid-gelatin and chitosan glycerophosphate. Carbohydr Polym. 2013;92:1512-1519.

8. Brink KS, Yang PJ, Temenoff JS. Degradative properties and cytocompatibility of a mixed-mode hydrogel containing oligo[poly(ethylene glycol)fumarate] and poly(ethylene glycol)dithiol. Acta Biomater. 2009;5:570-579.

9. Lian S, Xiao Y, Bian QQ, et al. Injectable hydrogel as stem cell scaffolds from the thermosensitive terpolymer of NIPAAm/AAc/HEMAPCL. Int J Nanomedicine. 2012;7:4893-4905.

10. Liu JP, Zhang LL, Yang ZH, Zhao XJ. Controlled release of paclitaxel from a self-assembling peptide hydrogel formed in situ and antitumor study in vitro. Int J Nanomedicine. 2011;6:2143-2153.

11. Wang WW, Deng LD, Liu SS, et al. Adjustable degradation and drug release of a thermosensitive hydrogel based on a pendant cyclic ether modified poly( $\varepsilon$-caprolactone) and poly(ethylene glycol)co-polymer. Acta Biomater. 2012;8:3963-3973.

12. Heilmann S, Küchler S, Wischke C, Lendlein A, Stein C, SchäferKorting M. A thermosensitive morphine-containing hydrogel for the treatment of large-scale skin wounds. Int J Pharm. 2013;444:96-102.

13. Dyondi D, Webster TJ, Banerjee R. A nanoparticulate injectable hydrogel as a tissue engineering scaffold for multiple growth factor delivery for bone regeneration. Int $J$ Nanomedicine. 2013;8:47-59.

14. Park KM, Lee SY, Joung YK, Na JS, Lee MC, Park KD. Thermosensitive chitosan - Pluronic hydrogel as an injectable cell delivery carrier for cartilage regeneration. Acta Biomater. 2009;5: 1956-1965.

15. Niranjan R, Koushik C, Saravanan S, Moorthi A, Vairamani M, Selvamurugan N. A novel injectable temperature-sensitive zinc doped chitosan/ $\beta$-glycerophosphate hydrogel for bone tissue engineering. Int J Biol Macromol. 2013;54:24-29.

16. Wang K, Xing JF, Li XY, Fu Q, Li WF. Fabrication of novel magnetic nanoparticles-coated $\mathrm{P}$ (styrene-itaconic acid-divinylbenzene) microspheres. Carbohydr Polym. 2012;87:2712-2717.

17. Zhang Z, Ni J, Chen L, Yu L, Xu JW, Ding JD. Biodegradable and thermoreversible PCLA-PEG-PCLA hydrogel as a barrier for prevention of post-operative adhesion. Biomaterials. 2011;32:4725-4736.

18. Abandansari HS, Aghaghafari E, Nabid MR, Niknejad H. Preparation of injectable and thermoresponsive hydrogel based on penta-block copolymer with improved sol stability and mechanical properties. Polymer. 2013;54:1329-1340.

19. Kang SW, Li Y, Park JH, Lee DS. pH-triggered unimer/vesicletransformable and biodegradable polymersomes based on PEG-b-PCLgrafted poly $(\beta$-amino ester) for anti-cancer drug delivery. Polymer. 2013;54:102-110.

20. Xin HL, Sha XY, Jian XY, Zhang W, Chen LC, Fang XL. Anti-glioblastoma efficacy and safety of paclitaxel-loading Angiopepconjugated dual targeting PEG-PCL nanoparticles. Biomaterials. 2012;33:8167-8176.

21. Mayr HO, Klehm J, Schwan S, et al. Microporous calcium phosphate ceramics as tissue engineering scaffolds for the repair of osteochondral defects: biomechanical results. Acta Biomater. 2013;9:4845-4855.

22. Li XY, Nan KH, Shi S, Chen H. Preparation and characterization of nano-hydroxyapatite/chitosan cross-linking composite membrane intended for tissue engineering. Int J Biol Macromol. 2012;50:43-49.

23. Wang HN, Li YB, Zuo Y, Li JH, Ma S, Cheng L. Biocompatibility and osteogenesis of biomimetic nano-hydroxyapatite/polyamide composite scaffolds for bone tissue engineering. Biomaterials. 2007;28:3338-3348.

24. Pan HB, Darvell BW. Solubility of TTCP and $\beta$-TCP by solid titration. Arch Oral Biol. 2009;54:671-677.

25. Wagoner Johnson AJ, Herschler BA. A review of the mechanical behavior of $\mathrm{CaP}$ and $\mathrm{CaP} /$ polymer composites for applications in bone replacement and repair. Acta Biomater. 2011;7:16-30. 
26. Rezwan K, Chen QZ, Blaker JJ, Boccaccini AR. Biodegradable and bioactive porous polymer/inorganic composite scaffolds for bone tissue engineering. Biomaterials. 2006;27:3413-3431.

27. Reddy S, Wasnik S, Guha A, Kumar JM, Sinha A, Singh S. Evaluation of nano-biphasic calcium phosphate ceramics for bone tissue engineering applications: in vitro and preliminary in vivo studies. J Biomater Appl. 2013;27:565-575

28. Rezaei A, Mohammadi MR. In vitro study of hydroxyapatite/ polycaprolactone (HA/PCL) nanocomposite synthesized by an in situ sol-gel process. Mater Sci Eng C. 2013;33:390-396.

29. Fan RR, Zhou LX, Song W, et al. Preparation and properties of g-TTCP/ PBS nanocomposites and its in vitro biocompatibility assay. Int J Biol Macromol. 2013;59:227-234.

30. Fan RR, Zhou LX, Li DX, Zhang DM, Wu M, Guo G. Preparation and characterization of composites based on poly (butylene succinate) and poly (lactic acid) grafted tetracalcium phosphate. J Macromol Sci B. 2013, DOI: 10.1080/00222348.2013.810104.

31. Fan M, Guo QF, Luo JC, et al. Preparation and in vitro characterization of dexamethasone-loaded poly(D, L-lactic acid) microspheres embedded in poly(ethylene glycol)-poly(\{varepsilon\}-caprolactone)-poly(ethylene glycol) hydrogel for orthopedic tissue engineering. J Biomater Appl. 2013;28:288-297.

32. International Organization for Standardization. Document 10993. Biological evaluation of medical devices. Part 5: Tests for in Vitro Cytotoxicity; 2009. Available from: https://archive.org/details/is.en. iso.10993.5.2009. Accessed October 24, 2013.
33. Weinand C, Pomerantseva I, Neville CM, et al. Hydrogel- $\beta$-TCP scaffolds and stem cells for tissue engineering bone. Bone. 2006;38:555-563.

34. Sohier J, Corre P, Weiss P, Layrolle P. Hydrogel/calcium phosphate composites require specific properties for three-dimensional culture of human bone mesenchymal cells. Acta Biomater. 2010;6:2932-2939.

35. Gong CY, Dong PW, Shi S, et al. Thermosensitive PEG-PCL-PEG hydrogel controlled drug delivery system: sol-gel-sol transition and in vitro drug release study. J Pharm Sci. 2009;98:3707-3717.

36. Ferraris S, Vitale-Brovarone C, Bretcanua O, Cassinelli C, Vernè E. Surface functionalization of 3D glass-ceramic porous scaffolds for enhanced mineralization in vitro. Appl Surf Sci. 2013;271:412-420. Available from http://www.sciencedirect.com/science/article/pii/ S016943321300295X. Accessed December 11, 2103.

37. Ferruti P, Mancin I, Ranucci E, De Felice C, Latini G, Laus M. Polycaprolactone- poly(ethylene glycol) multiblock copolymers as potential substitutes for di(ethylhexyl) phthalate in flexible poly(vinyl chloride) formulations. Biomacromolecules. 2003;4:181-188.

38. Zhang QY, Chen JY, Feng JM, Cao Y, Deng CL, Zhang XD. Dissolution and mineralization behaviors of HA coatings. Biomaterials. 2003;24:4741-4748.
International Journal of Nanomedicine

\section{Publish your work in this journal}

The International Journal of Nanomedicine is an international, peerreviewed journal focusing on the application of nanotechnology in diagnostics, therapeutics, and drug delivery systems throughout the biomedical field. This journal is indexed on PubMed Central, MedLine, CAS, SciSearch $\AA$, Current Contents ${ }^{\circledR} /$ Clinical Medicine,

\section{Dovepress}

Journal Citation Reports/Science Edition, EMBase, Scopus and the Elsevier Bibliographic databases. The manuscript management system is completely online and includes a very quick and fair peer-review system, which is all easy to use. Visit http://www.dovepress.com/ testimonials.php to read real quotes from published authors. 